current legislation. The fact is that there are no new powers and these patients still have to deteriorate and then be readmitted compulsorily before they can receive the treatment they need.

Fawad Kaiser, Associate Specialist, Kneesworth House Psychiatric Hospital, Bassingbourn-cumKneesworth, Royston, Hertfordshire SG8 5JP

\section{Is this informed consent?}

Sir: The Code of Practice (Department of Health \& Welsh Office, 1999) sets out in detail the basic principles governing consent. It is clear from this that in order to understand the nature, purpose and likely effects of a treatment patients require some awareness of their diagnosis. The Patient's Charter for Mental Health Services (Department of Health 1997) states that patients can expect "to be able to ask for an explanation of your diagnosis in plain language and to ask for more information if you do not understand". This raises the question as to how much psychiatric patients know about their formally allocated diagnoses, with the implication this has for consent issues.

We conducted a questionnaire survey of out-patient and day hospital attendees, under regular psychiatric follow-up, with a view to considering this issue locally. An impressive knowledge of diagnosis was demonstrated by those patients suffering schizophrenia $(72 \%, n=18)$, bipolar affective disorder $(79 \%, n=14)$ and depressive disorders $(89 \%, n=27)$. However, those with a primary diagnosis of personality disorder or substance misuse problems demonstrated considerably less awareness of this in their responses (with only $25 \%, n=24$ and $42 \%, n=12$, respectively). Whether this means that they have never been informed of the diagnosis, did not understand the explanation, are unable to recall it or choose to disregard it is unclear. However, if there is genuine ignorance among this group as to what it is that is being treated, then careful thought must be given to matters of consent. Are the patients consenting to the same thing as the treating psychiatrist imagines? Can you have informed consent in the absence of diagnostic awareness?

DEPARTMENT OF HEALTH (1997) The Patient's Charter for Mental Health Services. London: Department of Health.

\section{— \& WELSH OFFICE (1999) Code of Practice. London:} HMSO

John Patrick Stephens, Senior Registrar in Psychiatry, Alderney Community Hospital, Ringwood Road, Poole, Dorset BH12 4NB

\section{Calman reforms}

Sir: I was interested to read Cavanagh \& Haut's survey of higher psychiatric trainees to assess satisfaction with changes brought about by the Calman reforms (Psychiatric Bulletin, August 1999, 23, 493-496). The survey uncovered dissatisfaction with the new specialist registrar (SpR) grade, which took the place of the senior registrar (SR) grade in 1996. Little objective evidence was found of differences between the two grades. However, one such difference is that of pay scales. The abolition of the registrar grade has meant that trainees remain on the senior house officer pay scale until they are appointed as SpRs. In addition to this, the SpR scale starts at $f 23300$, compared with $f 26840$ on the SR scale, and only reaches the higher figure at the fourth point of the SpR scale. Therefore, rather than the reforms putting "training at the top of the agenda" (Smith, 1994), they could be more cynically viewed as a cost cutting exercise. The authors found that more flexibility for time in higher training and restoring the SR title would help to improve morale. Surely restoring SR pay would further contribute to such an improvement.

SMITH, R. (1994) Challenging doctors: an interview with England's chief medical officer. British Medical Journal, 308, 1221-1224.

Antony Gahan, Specialist Registrar, Drug Dependency Unit, Homerton Hospital, Homerton Row, London E9 6SR

\section{Use of Section 62 in clinical practice}

Sir: Recent articles concerning the use of the Mental Health Act have tended to focus on the use of commonly used parts of the Act such as Sections 2 and 3 (Turner et al, Psychiatric Bulletin, October 1999, 23, 578-581). We chose instead to survey the use of Section 62 (urgent treatment) across three psychiatric units in Bristol for the years 1990-1997.

During the study period 60 patients received urgent treatment. The frequency of use varied across the units as follows: Unit A, 14 cases; Unit B, eight cases; Unit $C, 38$ cases. On all occasions the urgent treatment used was electroconvulsive therapy (ECT).

We found that in $18 \%$ of cases Section 62 was applied more than once during a course of ECT seemingly due to delays in gaining a second opinion

The Code of Practice (Department of Health \& Welsh Office, 1999), places the responsibility for devising a form for
Section 62 (as well as monitoring its use) upon the managers of individual trusts. Although (different) forms were available on all three units, the subsequent filing of documentation varied between sites. Only one manager kept both a record detailing the use of the section as well as a copy of the form separate from the notes.

As far as we are aware this is the only published survey concerning the use of Section 62. The variation in use of Section 62 across units along with its occasional multiple use would seem to indicate the need for a standardised form as well as a more detailed review in the Mental Health Act Commission's biennial report to Parliament.

DEPARTMENT OF HEALTH \& WELSH OFFICE (1999) Code of Practice. Mental Health Act 1983. London: HMSO.

*I. Johnson, Senior Registrar, Cossham Hospital, Lodge Road, Kingswood, Bristol BS15 1LF, M. Curtice, Senior House Officer, New Friends Hall, Heath House Lane, Stapleton, Bristol BS16 1EQ

\section{Recommended reading for trainees}

Sir: I read with pleasure Henry Rollin's Psychiatry at 2000 (Psychiatric Bulletin, January 2000, 24, 11-15). I shall recommend it to trainees.

To add a footnote, I have the Annual Report for the Cumberland and Westmorland Lunatic Asylum for 1892, written by the Medical Superintendent, Dr J. A Campbell. That year the Asylum had 580 inmates and a total of 52 attendants.

Dr Campbell includes a summary of the Asylum's work between 1882 and 1892. There had been 1537 admissions of whom 679 were discharged recovered and 503 (33\%) had died. There were two suicides and three 'fatal casualties'. Most of the deaths (29\%) were due to physical causes. One hundred and eighty-eight had cerebral or spinal disease, 113 had senile exhaustion', 77 were diagnosed with general paralysis of the insane and 62 died of tuberculosis.

These figures suggest that the asylums unintentionally provided chronic or terminal care for non-mental disorders. The social value of this activity deserves remembrance in accounts of 19th century mental health provision. If these deaths are excluded then the average discharge rate was $62 \%$ in spite of the lack of effective treatments.

Alasdair J. Macdonald, Consultant Psychiatrist, Garlands Hospital, Carlisle, Cumbria CA1 3SX 